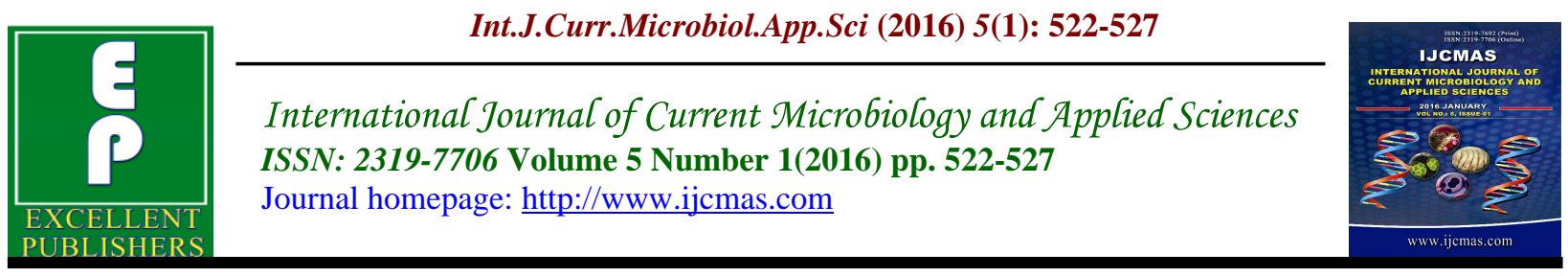

Original Research Article

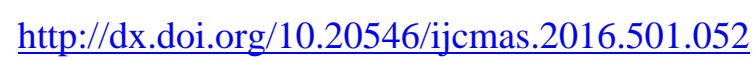

\title{
Circadian Variation in Oxidative Stress Markers in Alcoholic Hepatitis Patients
}

\author{
Sanjay Bhatt ${ }^{1 *}$, Maliyannar Itagappa ${ }^{1}$, Bindu Sati $^{2}$, J.B.Gogoi ${ }^{2}$, \\ Monika Pathaniya ${ }^{2}$, Rana Shinde ${ }^{2}$, and Jyoti Batra ${ }^{3}$ \\ ${ }^{1}$ Department of Biochemistry, R.M.R.I, Bareilly, India \\ ${ }^{2}$ Department of Medicine, V.C.S.G.G.I.M.S and R Srinagar Garhwal, India \\ ${ }^{3}$ Department of Biochemistry, Santosh Medical College and Hospital, Ghaziyabad, India
}

*Corresponding author

\section{A B S T R A C T}

Keywords

Circadian

Variation,

Oxidative Stress

Markers,

Alcoholic

Hepatitis

Article Info

Accepted:

22 December 2015

Available Online:

10 January 2016
The circadian periodicity of plasma lipid peroxide levels and activities of superoxide dismutase (SOD), catalase (CAT) and glutathione peroxidase (GPx), glutathione reductase (GSH), total antioxidant status were studied in 30 clinically, alcoholic hepatitis proven fresh cases (age: 18-70 years) and 30 age matched healthy volunteers with diurnal activity from 06:00 to about 22:00 and nocturnal rest. A marked circadian variation in plasma lipid peroxide level was recorded in healthy subjects and alcoholic patients with significant amplitude and acrophase around 16:21 and 17:12 respectively. The acrophase tended to be delayed in alcoholic patients. Furthermore, a statistically significant circadian rhythm was found in SOD, CAT and GPx, GSH, TAS, MDA activities in normal volunteers and alcoholic hepatitis patients. SOD and CAT enzyme activity was noted to be maximum at 06:00 and minimum at 00:00 in alcoholic hepatitis patients. The circadian acrophase for GPx activity was recorded at 16:15 in normals and around 22:45 in patients. Moreover, the activity was found to be decreased at all sampling hours during 24-hours sleep-awake period in patients in comparison to healthy counterparts. The MESOR and circadian amplitude also decreased markedly. The decreased activity of measured antioxidant enzymes in Alcoholic hepatitis patients could probably be associated with oxidative stress and/or decreased anti-oxidant defensive mechanism in such patients.

\section{Introduction}

Alcoholic Hepatitis is an alcohol induced disease with genetic, psycho-social and environmental factors influencing its development and manifestations. The disease is often progressive and is considered to be a major cause of morbidity and mortality(1-5). In recent years, oxidative stress has been implicated in the path physiology of a large number of disease or disorders which are initiated and /or exacerbated by pro-oxidants such as various drugs including alcohol and food additives. 
Besides, ingested alcohol produces striking metabolic imbalances in the liver. It leads to the formation of reactive oxygen species (ROS).Inadequate removal of ROS may cause cell damage by attacking membrane lipids, proteins and inactivating enzymes thus mediating several forms of tissue damage(6-8). At present, except for the abstinence of alcohol abuse, there is no effective modality of either prevention or treatment. The incidence of Alcohol Hepatitis is increasing day by day specially in the developing countries including India(9-11). The study was done with the objectives to investigate the oxidative damage and the efficiency of antioxidant defense system in patients of alcoholic hepatitis in the socioeconomic belt of Srinagar, Garhwal, Uttarakhand.

\section{Materials and Methods}

Thirty clinically, pathologically proven fresh cases of alcoholic hepatitis (group A; age: 21-45 years) and 30 clinically healthy volunteers of either sex (group B; age: 17-40 years) were included in this study. Only minimal and moderately advanced patients of alcoholic hepatitis were included in the present study (13). All participants were synchronized for one week with diurnal activity from about 6:00 to about 22:00 hrs. and nocturnal rest. All subjects took their usual (although not identical) meals three times daily; breakfast around 8:30 a.m., lunch around 13:30 p.m. and dinner around 20:30 p.m., without any change in their usual fluid intake. The burden of environmental temperature and pollution, if any, was common to all participants. Prior to the blood sample collection, the participants refrain from taking any drugs/preparation that would affect or alter the oxidative stress, its defensive mechanism, level and rhythm. Six millilitres of blood was collected from each subject at fixed time points for one complete 24 hour cycle, at 06:00, 12:00, 18:00 and 00:00 hrs. in plain and sterile vials containing heparin as anticoagulant. The plasma was separated and analyzed for lipid peroxides in terms of malondialdehyde (MDA) (14). The haemolysate was prepared from the red cells and used for the measurement of the activities of enzymes superoxide dismutase (SOD), catalase (CAT) and glutathione peroxidase $(\mathrm{GPx})(15,16,17)$. Data were evaluated by conventional statistical analyses and by the single- and populationmean cosinor procedures $(18,19)$. Accordingly, the MESOR (a rhythmadjusted mean, usually more precise and more accurate than the arithmetic mean), the circadian amplitude (a measure of half the extent of predictable change within a 24hour cycle; the double amplitude being a measure of total extent of change within a day predictable by the curve fitted); and the circadian acrophase (a measure of the timing of overalll high values of the fitted 24-hour cosine function) were estimated. Rhythm detection was assessed by the zero amplitude (no rhythm) test at the 5\% probability level.

\section{Results and Discussion}

Mean plasma MDA concentration found to be $2.90 \mathrm{nmol} / \mathrm{ml}$ plasma at 18:00hrs., decreased markedly during the rest of the period, reaching a minimum at 06.00 in healthy volunteers. These variations at different collections hours during at 24-hour cycle were significant $(p<0.001)$ with acrophase around 16:21. SOD activity was calculated to be maximum at 06.00 and minimum at 00.00 in alcoholic hepatitis patients. Catalase activity was found to be 14.55 (units/ml RBCs) at 06.00, which decreased gradually to a minimum at 18.00 in healthy volunteers. Maximum catalase activity was calculated to be 11.18 ( units/ml 
RBCs) at 06.00 in alcoholic hepatitis patients which declined regularly throughout the 24-hour cycle reaching a minimum at 00.00 with a mean of 10.47 (units $/ \mathrm{ml}$ RBCs). Mean GPx activity was observed to be maximum at 18.00 and minimum at 00.00 in healthy control. However, circadian rhythm was noticed to be dearranged in alcoholic hepatitis patients with maximum at 12.00 .

Table.1 Distribution of Patients of Alcoholc Hepatitis According to Groups

\begin{tabular}{|l|l|}
\hline Group & Number of Patients \\
\hline A & 30 \\
B & 30 \\
\hline Total & 60 \\
\hline
\end{tabular}

Table.2 Serum Superoxide Dismutase (SOD), Malondialdehyde (MDA), Glutathione Peroxidase (GPx), Glutathione Reductase (G-SH), Catalase and Total Antioxidant Status (TAS) Levels amongst Normal Healthy Individuals and Patients of Alcoholic Hepatitis

\begin{tabular}{|l|l|l|}
\hline Parameters & Control $(\mathbf{n}=30)$ & Patients $(\mathbf{n}=30)$ \\
\hline SOD & $19.95 \pm 0.05$ & $16.05 \pm 0.09$ \\
MDA & $2.28 \pm 0.03$ & $2.90 \pm 0.03$ \\
GPx & $4.14 \pm 0.03$ & $2.88 \pm 0.03$ \\
G-SH & $5.15 \pm 0.02$ & $2.93 \pm 0.03$ \\
TAS & $2.80 \pm 0.03$ & $2.10 \pm 0.02$ \\
Catalase & $14.55 \pm 0.04$ & $11.18 \pm 0.08$ \\
\hline$\left.{ }^{* P}<0.001^{\prime}\right]$
\end{tabular}

A marked circadian variation in plasma MDA level was recorded in healthy Indians and alcoholic hepatitis patients with significant amplitude and acrophase around 16:21 and 17:12 respectively. The circadian acrophase of plasma MDA levels occurred around 50 minutes later in patients in comparison to healthy controls; however, there was no significant difference in the MESORS of the two groups.

The circadian amplitude tends to be increased in alcoholic hepatitis patients in comparison to the healthy volunteers. However, plasma lipid peroxide levels in terms of MDA concentrations were normal in the present study, though there was a shift in circadian acrophase exhibiting the involvement of oxidative stress in such situations. Moreover, only minimal and the moderately advanced group of patients were included in this study. The present observations regarding circadian nature of plasma MDA levels in healthy volunteers were in agreement with other reports (2022). There are no reports regarding circadian variations of circulating lipid peroxides in alcoholic hepatitis patients under tropical conditions.

A statistically significant circadian rhythm was recorded in SOD, CAT and GPx concentrations in clinically healthy subjects and alcoholic hepatitis patients. SOD activity was found to be maximum at 06:00 hrs. and minimum at 00:00 hrs. in patients. Moreover, the activity was noticed to be decreased at all sampling hours during a 24- 
hour sleep-awake period in patients in comparison to their healthy counterparts. The MESOR and circadian amplitude also decreased markedly in alcoholic hepatitis patients suggesting decreased SOD concentrations. The circadian acrophase occurred 30 minutes later in patients as compared to healthy volunteers. Similarly, CAT activity was also noticed to be reduced at all collection hours in patients with decreased MESOR and circadian amplitude. The circadian acrophase occurred around 1 hour and 30 minutes later in patients. GPx activity further decreased at all collection hours in alcoholic hepatitis patients with maximum activity at 00:00 and minimum at 12:00. The MESOR and circadian amplitude decreased markedly. Moreover, there was maximum swing and altered rhythm in the activity of this important antioxidant enzyme where the circadian amplitude was found to occur about 6 hours and 30 minutes later in patients in comparison to healthy subjects(24-30).

The decreased concentration of measured antioxidant enzymes in alcoholic hepatitis patients could probably be associated with oxidative stress and/or decreased antioxidant defense mechanism. GPx activity, found to be decreased at all sampling hours in patients in comparison to healthy subjects, clearly exhibited an imbalance between oxidant and antioxidant defensive systems in the human body under such pathological situations. This probably could be the important factor for the etiopathogenesis of the disease and needs further confirmation for better supplementation of transition metals and micronutrients along with antioxidant vitamins with known antihepatic regimen(31-35).

Furthermore, supplementation of today's cocktail of hepatic drugs with antioxidant vitamins and nutrients should be advocated in the right combination and for the right length of time according to the biological clock for better therapeutic utilization and efficiency.

\section{References}

1. Aebi, H. and Suter, H. "Protective function of reduced glutathione against the effect of pro-oxidative substances and of irradiation in the red cell' '. In Flone, L.,Besnhar, H.C. Ceditors,. Glutathione. Stuttgart: Georg Thieme; 192 - 199, 1974.

2. Ahmad R, Tripathi A K, Tripathi P, Singh R, Singh S, Singh R K. "Studies on lipid peroxidation and nonenzymatic antioxidant status as indices of oxidative stress in patients with chronic myeloid leukemia".Singapore Med J; 51(2) : 110, 2010.

3. Albano E. Alcohol, oxidative stress and free radical damage. ProcNutrSoc 2006; 65:01-13.

4. Alcohol and Health. (U.S. department of Health and Services), Seventh Special Report to the U.S. Congress. 1990.

5. Andreasson S, AllebeckP, Romelsjo A. Alcohol and mortality among young men: longitudinal study of Swedish conscripts. Br Med J. 1988; 296: 10211025.

6. Beers RF, Sizer IW. A spectrophotometric method for measuring the breakdown of hydrogen peroxides by catalase. J BiolChem; 1952; 195: 133-140.

7. Bergmeyer HU, Bernt E. Glutamate oxaloacetate transaminase; Glutamate pyruvate transaminase. In: Methods of Enzymatic Analysis (Ed. Bergmeyer HU) Academic Press, New York, pp. 1963, 837-853.

8. Breus, T.K.,Cornelissen, G., Halberg, F. and levitin, A.D.,"Temporal 
associations of life with solar and geophysical activity" Ann. Geophys; 13:1211 - 1222, 1995.

9. Breus, T.K.,Halberg, F. and Cornelissen, G., "Influence of solar activity on the physiological rhythms of biological system". Biofizika (Russian); 40(4):737 - 7481995.

10. Bunning E. "The physiological clock; endogenesis; diurnal rhythms and biological chronometry". Academic, New York, 1964.

11. Bunning, E.,"The physiological clock; Circadian rhythms and biological chronometery. $3^{\text {rd }}$ edn. Springer, Berlin, Heidelberg, New York, 1973.

12. Chronomics and Chronobiology in health and disease. Singh RK.Indian Journal of clinical Biochemistry. 24(4) 319-323, 2009.

13. Conroy, R.T.W.L and Mills, J.N. "Human circadian rhythms". Churchill,London 1970.

14. Das SK, Nayak P, Vasudevan DM. Biochemical Markers for Alcohol Consumption. Ind J ClinBiochem. 2003; 18(2): 111-118.

15. Das SK, Vasudevan DM. Monitoring oxidative stress in patients with nonalcoholic and alcoholic liver diseases. Ind J ClinBiochem. 2005; 20(2). (In Press)

16. Frienhel, N., Aky, R.A, Singer, D.L, Cohen, A.K.(1985). Alcohol hypoglycemia IV. Current concepts of its pathogenesis. Diabetes 4, 350-361.

17. Goldberg, M.D.; and Spooner, J.R.. In: Methods of Enzymatic Analysis (ed. Bergmayer), Vol. III, $3^{\text {rd }}$ edn. Academic Press, Inc., Florida, 1983; pp. 258-265.

18. Grant BF, Harford TC. Epidemiology of alcoholic liver disease. Semin Liver Disease 1988; 8:12-25.

19. Gupta S, Pandey R, Katyal R, Agarwal HK, Agarwal SK. Lipid peroxide and antioxidant status in alcoholic liver disease. Ind J ClinBiochem 2005; 20(1): 67-71.

20. Halberg, F. "Implications of biologic rhythms for clinical practice". HospPract.; 12:139-49, 1977.

21. Halberg, F. Lornelissen, G.,Bakken, E., "care giving merged with chronobiologic outcome assessment, research and education in health maintenance organization". Prog. Clin Biol. Res; 3418: 491 - 549, 1990.

22. Halberg, F. Quo vadis basic and clinical chronobiology: promise for health maintenance. Am J Anat; 168:543-94, 1983.

23. Halberg, F., "Chronobiology”. Ann. Rev Physiol; 31; 675 - 725; 1969.

24. Halliwell, B.,Gutteridge, J.M.C, "Free radicals in biology and medicine" $3^{\text {rd }}$ ed. Oxford kingdom, Oxford University press, 1999.

25. Halliwell; B,. Antioxidants in human health and disease". Annu. Rev. Nutr; 16: 33 - 50, 1996.

26. Hans, E. and Halberg, F., "The Circadian time structure". NATO Adv. Study Inst [D]: 47 - 94, 1980.

27. Harman, D., "Role of free radicals in aging and disease". Annals of New York Academy of Sciences; 673: 126 $141 ; 1992$.

28. Haus E, Touitou Y. "Chronobiology in laboratory medicine". In: Touitou Y, Haus E, editors. Biologic rhythms in clinical and laboratory medicine. Springer-Verlag; Berlin, Heidelberg, New York: pp. 673-708, 1992.

29. Hirnwich, H.E., Nahum, L.H., Pakieten, N., Fazekas, J.F., DU Bots, H. (1982). Effects of alcohol on metabolism. Am.J.Physiol. 101, 57-68.

30. Irshad M, Chaudhuri PS. "Oxidantantioxidant system: role and significance in human body". Indian J ExpBiol; 40:1233-9, 2002. 
31. Jose C. Fernández-Checa, Ph.D., Neil Kaplowitz, M.D., Anna Colell, and Carmen García-Ruiz, Ph.D. Oxidative Stress and Alcoholic Liver Disease: RESEARCH UPDATE.

32. Kolanjiappan, k. Manoharan, S. and Kayalvizhi, M. (2002).Measurement of erythrocyte lipids, lipid peroxidation, antioxidants and osmotic fragility in cervical cancer patients. Clin. Chin. Acta. 326, 143-149.

33. Langseth, L, "Oxidants; antioxidants and disease prevention". Belgium,
International Life Science Institute, 1996.

34. Liber CS. Alcohol and liver: metabolism of alcohol and its role in hepatic and extrahepatic diseases. Mt Sinai J Med 2000; 67 (1): 84-94.

35. Liber CS. Biochemical and molecular basis of alcohol induced injury to liver and other tissues. N Eng J Med 1988; 319:1639-1650.

\section{How to cite this article:}

Sanjay Bhatt, Maliyannar Itagappa, Bindu Sati, J.B.Gogoi, Monika Pathaniya, Rana Shinde, and Jyoti Batra. 2016. Circadian Variation in Oxidative Stress Markers in Alcoholic Hepatitis Patients. Int.J.Curr.Microbiol.App.Sci. 5(1): 522-527 hittp:///xx.doi.org/10.20546/ijcmas.2016.501.052 